\title{
SW Origin of North Pacific's Wide Warm Surface Current
}

\section{Kern E. Kenyon}

4632 North Lane, Del Mar, USA

Correspondence to: Kern E. Kenyon, kernken@aol.com

Keywords: North Pacific Ocean, Wide Warm Surface Flow, Origin: Western Tropics

Received: May 5, $2018 \quad$ Accepted: June 25, $2018 \quad$ Published: June 28, 2018

Copyright $\odot 2018$ by author and Scientific Research Publishing Inc.

This work is licensed under the Creative Commons Attribution International License (CC BY 4.0).

http://creativecommons.org/licenses/by/4.0/

\section{(c) $\underset{\mathrm{BY}}{\mathrm{BY}}$ Open Access}

\section{ABSTRACT}

There is a long and wide continuous trough of deep mixed layers connecting the tropical western North Pacific Ocean with the offshore waters of the coast of California. Relatively warm water that is nearly uniform vertically fills the trough, which is concluded here to be a northeastward flow joining the wide warm surface current at mid-latitudes off California documented earlier. Evidence for the trough comes from a North Pacific atlas based on very many individual mixed layer depth data points, taken over a 27 -year period, compiled (averaged) in monthly mean charts with contours of constant mixed layer depth displayed. BTs (bathythermographs) were used to record temperature versus depth continuously from which the mixed layer depths were determined. Centerline curves, connecting the deepest mixed layer depths, which approximate the middle of the troughs, are constructed from the atlas and are presented for all twelve months. In going from west to east, these curves bend counterclockwise, gradually most of the way then more markedly near California. The curves for the summer months come closer to California than any of the other ones do, suggesting that the warm current itself is nearest to California in summer. Confirmation of the prediction awaits future efforts.

\section{INTRODUCTION}

A wide warm surface current, flowing northeast just off California, was discovered in sea surface temperature data during the early 1970s in the following way. Millions of individual ship-injection temperatures had been combined into monthly means for most five degree latitude/longitude squares north of $20 \mathrm{~N}$ since 1947. Starting at California and moving west along latitudes 35 and $40 \mathrm{~N}$, the SSTs in that unpublished data set steadily rise to a maximum and then fall off again over a longitude range of about 4,000 $\mathrm{km}$. This longitudinal maximum in sea surface temperatures exists in every monthly mean chart at both latitudes over a 30-year period, qualifying such a feature to be called permanent. Reality of the longitudinal SST maximum has been verified several times by comparison with independent more closely spaced measurements using more accurate thermometers made on individual oceanographic cruises. A logical expla- 
nation is that the only way to sustain the in situ longitudinal SST maximum on a permanent basis, with heat always leaking out into the atmosphere, is to constantly import warmer water into the region from somewhere to the south where the water is warmer.

Therefore, a very wide northward flowing warm surface current off California was postulated [1]. Where does it come from? Relevant to answering this question is the fact that the longitudinal SST maximum along $35 \mathrm{~N}$ is always slightly west of that along $40 \mathrm{~N}$. So the warm stream off California is deduced to flow northeast at mid-latitudes, not due north. But then the signature feature of the current, the longitudinal SST maximum, fades away as the latitude decreases. This might be expected, for example, if the flow of warm surface water had a direction that was more east than north at lower latitudes. Another method needs to be found to locate the origin of the warm water in the northeastward surface current, presumably involving acquiring subsurface data. Otherwise the tracking of numerous drifting floats might be envisioned. In both cases, difficulties and expenses are anticipated.

Making a guess about the origin of the warm water off California is easily done: the western tropics of the North Pacific where the highest SSTs of this ocean are always to be found. How does one prove that though? A form of proof lies in the interpretation of comprehensive data presentations contained in an atlas that has been available since 1976, but apparently that interpretation has not been stated in print before.

\section{OBSERVATIONS}

Everything that follows next is hypothesized, using a chain of reasoning, from the immense amount of work done in making an enlightening oceanographic atlas of the whole North Pacific, constructed under the direction of Margret Robinson [2], which in turn is based almost entirely on very many individual BT measurements obtained over a 27 year period starting in 1942 and compiled into monthly mean charts. A BT, or bathythermograph, was a rather crude instrument, but it had one redeeming feature of interest here: continuous recording of temperature against depth in the upper one hundred meters of the ocean. Therefore, from it could be obtained fairly accurate mixed layer depths, which are the depths where the temperature changes from being very nearly a constant, starting at the sea surface, down to where the temperature starts rapidly decreasing with increasing depth, called the thermocline. The thermoclines occur almost always everywhere in the open ocean, whereas there is a particular large scale region of the very deep mixed layers that is permanent. Since the old style BT is no longer used, the North Pacific atlas based on BT data may remain unique.

Most interesting for the present purpose are twelve charts in the atlas, one for each month, exhibiting contours of the mean depth of the top of the thermocline, which the atlas states are equivalent to contours of the depth of the mixed layer. Waiting to be glanced at, and enhanced by coloring used in these charts, is a remarkably coherent structure: a very long and wide trough of relatively deep mixed layers. It is present in all 12 months and it extends most of the way across the ocean starting out in the tropical west with a small angle north of east that gradually becomes more northward when approaching California. Also this mixed layer trough appears to be roughly in the same location from one month to the next. Based on 27 years of data, the deep mixed later trough feature has earned the right to be called permanent, although it has no name.

Presented in Figures 1-3 are the twelve centerlines of the monthly mean deep mixed layer troughs, consecutively with four per graph (Figure 1 has the centerlines for January, February, March and April, etc.). These were traced one at a time by hand on a light table from the atlas charts by continuously connecting the greatest depths along a line, which always curved counterclockwise from west to east. In Figure 1 one centerline represents both January and February because these two curves are basically indistinguishable. And in Figure 2 two curves are nearly identical: June and July. There is a black dot in Figure 1 that indicates the longitude of the mixed layer depth at the centerline of the wide warm surface current along $35 \mathrm{~N}$ obtained in March and April, 1976 on an east/west hydrographic section [3], several years after the atlas was published. Location of the dot is consistent with those of the centerline curves for March and 


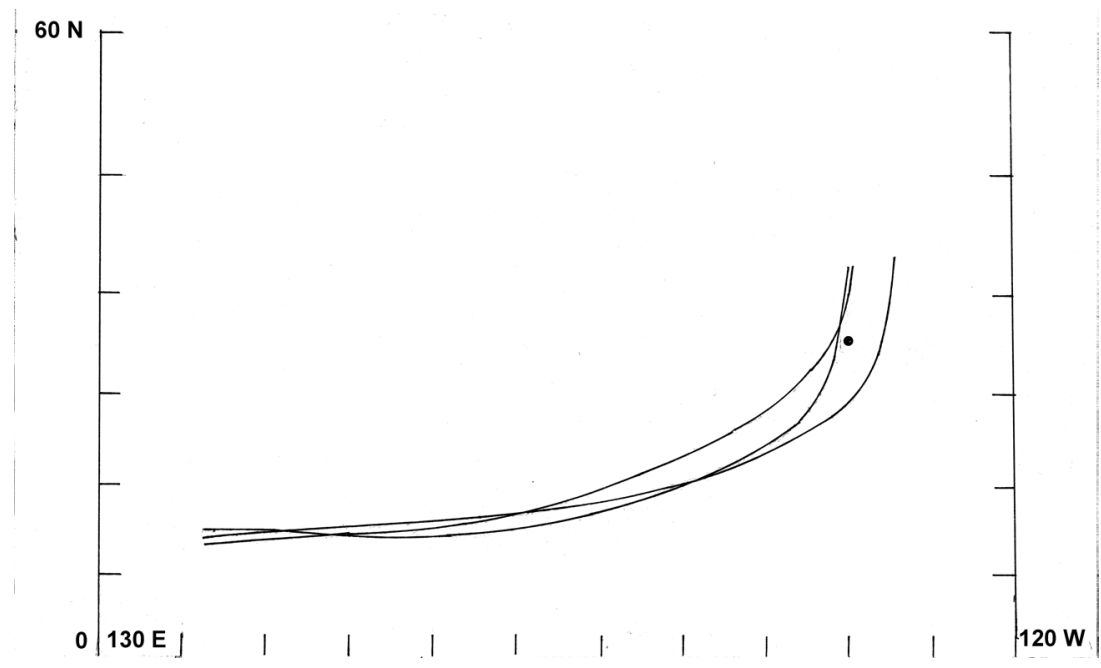

Figure 1. Centerline curves of troughs in deep monthly mean mixed layer depths obtained from Reference [2]. Clockwise from the left the northeast ends of the curves are for January-February, March, and April. Longitude range of the horizontal axis is from $130 \mathrm{E}$ on the left to $120 \mathrm{~W}$ on the right. Latitude range of the vertical axis is from $0 \mathrm{~N}$ at the bottom to $60 \mathrm{~N}$ at the top.

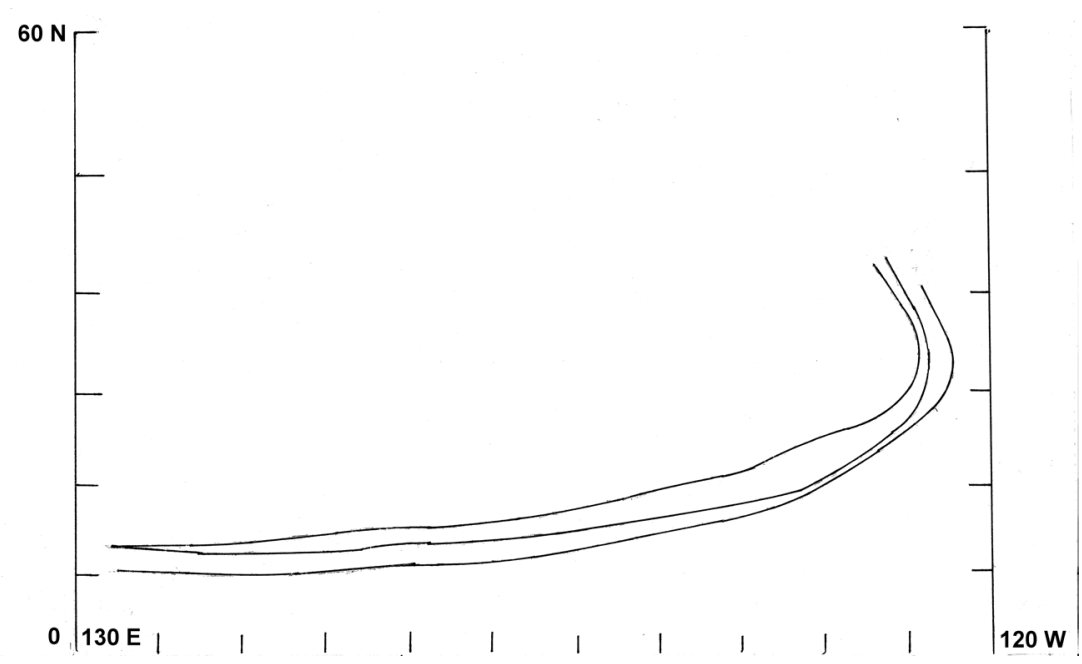

Figure 2. Same as Figure 1 except clockwise from the left the northeast ends of the curves are for May, August, and June-July.

April. Two examples of the mixed layer depth charts straight out of the atlas are shown in Figure 4 and Figure 5, one for the cold season (February) and the other from the warm season (July).

Upon first looking at Figure 4 or a similar one for January, my anticipation was off the mark due to previous experiences. When a warm surface layer current heads north at mid-latitudes in the cold season, conditions seemed right (by assumption) for heat to leak out of the ocean into the atmosphere and to cool the sea surface as a consequence, which apparently produced the observed deep mixed layers of $100 \mathrm{~m}$, or slightly more, observed along $35 \mathrm{~N}$ by penetrative convection. But when looking at low latitudes in the western North Pacific, where the surface current in question is apparently more east than north, I was amazed to find such deep mixed layers in a long wide band in the cold season. An even greater surprise to me is that along the centerline of the mixed layer trough, deep mixed layers, though somewhat shallower, 


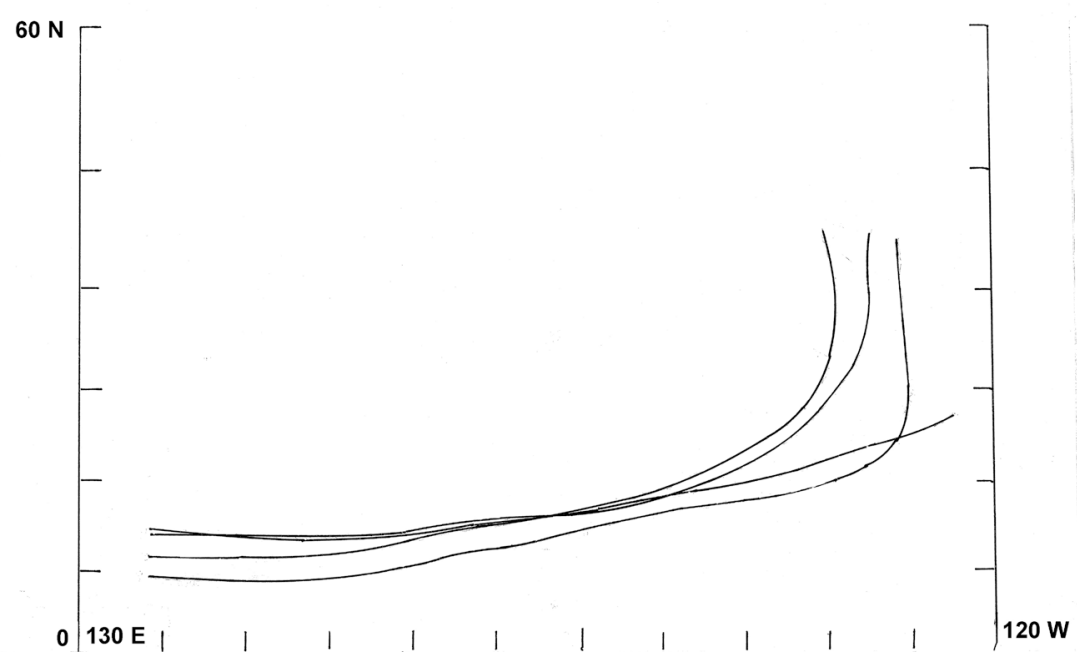

Figure 3. Same as Figure 1 and Figure 2 except clockwise from the left the northeast ends of the curves are for December, November, September, October.

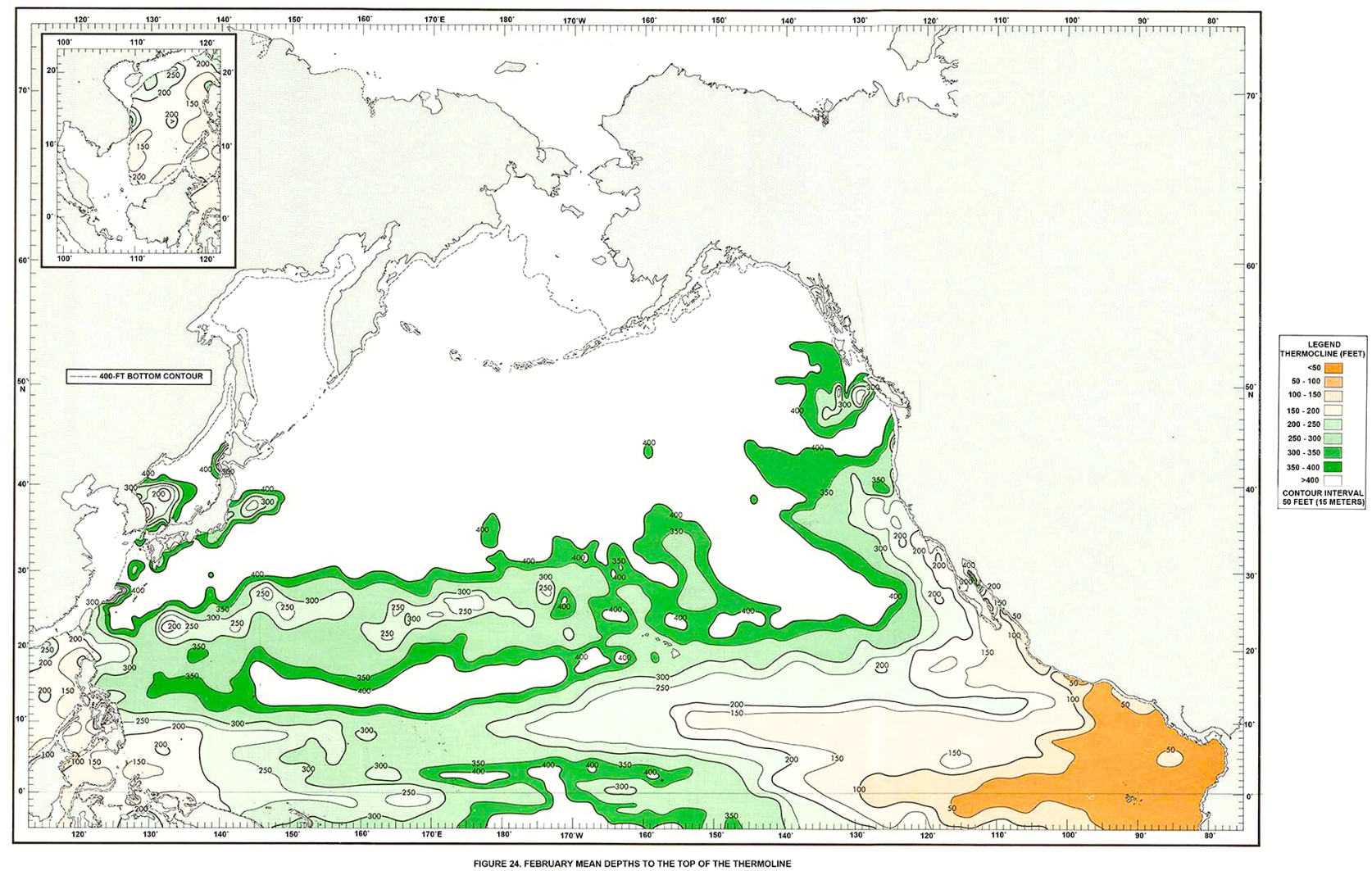

Figure 4. Monthly mean mixed layer depth contours for the North Pacific for February scanned from Reference [2]. Contour intervals are $50 \mathrm{ft}$.

occur even in the summer months. Therefore the atlas shows no seasonal thermoclines at the tops of the mixed layers within the troughs in summer. In summary, this suggests that the heat flow in the centerline region in particular is always one way: from ocean to atmosphere.

If one reads the classical physical oceanographic works by Sverdrup et al., Defant, and Neumann and 


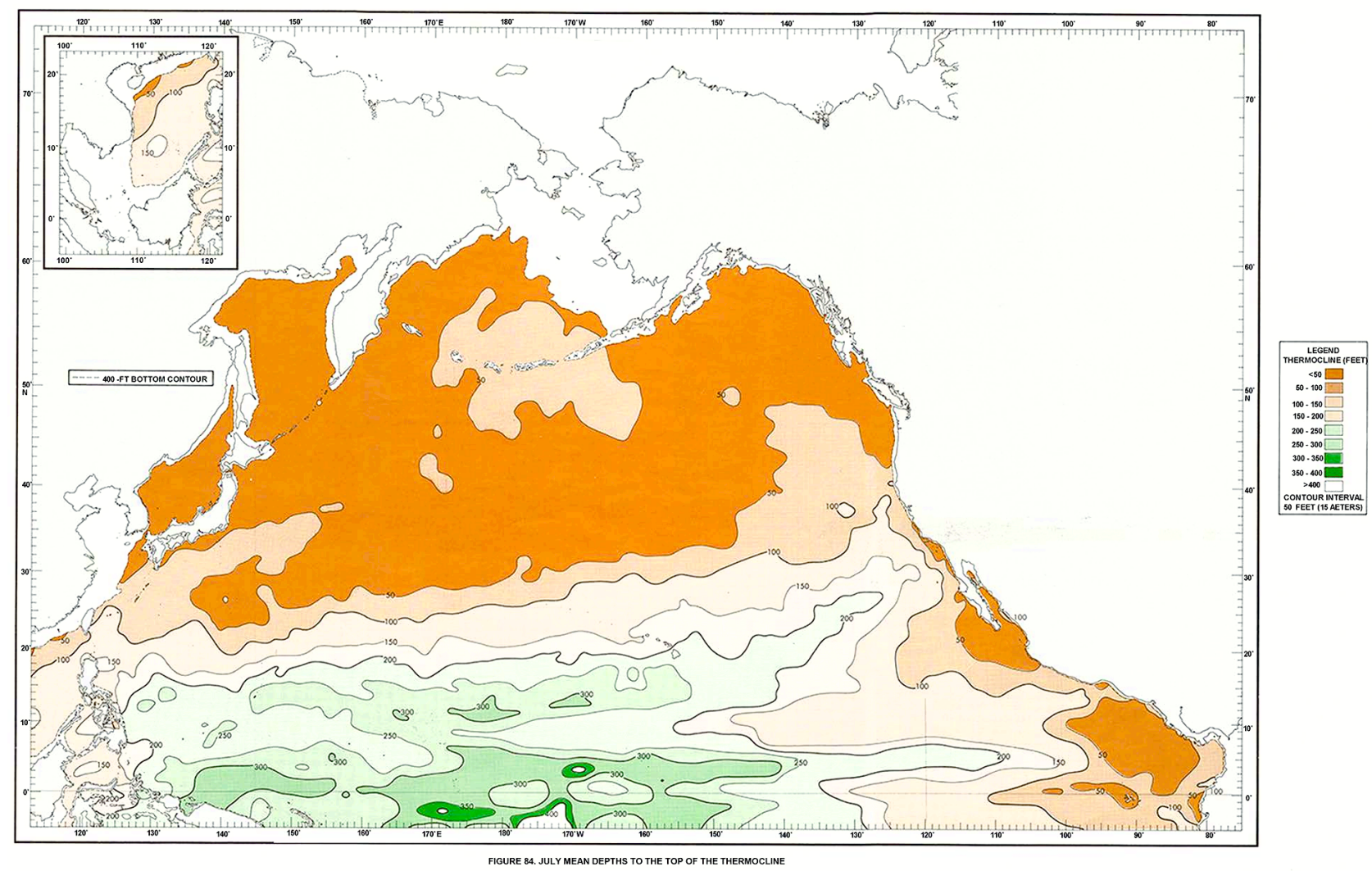

Figure 5. Same as Figure 4 except for July.

Pierson, for example, discussion gives out that the atmospheric literature of that time, which I have not seen, claims that the atmosphere, not the ocean, does most of the necessary job of transporting excess heat, due to solar radiation, from low to high latitudes. That I find somewhat hard to believe in view of the fact that most of the sun light basically passes right through the air and gets absorbed in the ocean, as is well known. But now evidently there is a way the ocean can start giving heat back to the atmosphere within a more banded structure than previously believed perhaps: all along the centerlines of the deep mixed layer troughs of Figures 1-3.

\section{DISCUSSION}

A few additional characteristics illustrated in Figures 1-3 are pointed out next. They are perhaps too tentative to be identified as results. First, on the western side of the ocean basin the centerline curves are generally clumped together more closely than are the ends of the lines on the eastern side. There is also moderately strong evidence that the centerlines come closer to California in the summer months (Figure 2 ) than in the colder months (Figure 1 and Figure 3). In fact all of the curves in Figure 2 have a nearer approach to California than any of the curves in Figure 1 and Figure 3 do. If this turns out to be true, then the implication follows that the wide warm surface current itself advances further eastward in summer, especially in June and July, than at any other time of year. [Incidentally, all the centerline curves happen to either intersect the Hawaiian Islands or come very close to them.]

Before continuing the discussion, a cautionary note is brought up: spatial and temporal aliasing inherent in the observational network on which the atlas is founded. However, for the permanent large-scale phenomenon under consideration here, the problem of aliasing in general is not expected to be an overwhelmingly important issue. In Figure 3 the northeastern end of the October centerline curve looks peculiar, or unfinished, in relation to the other curves, but it has been checked that it was copied correctly from 
the atlas. Perhaps aliasing due to lack of data is responsible in this particular case.

What the SST analyses suggested early on [4], through the longitudinal maxima at mid-latitudes, was potentially quite different. Twenty year means showed the SST maxima at both 35 and $40 \mathrm{~N}$ shifting significantly westward in summer. Later it was discovered that the reason for the westward shift was tied up with a second wide warm northward surface surge to the west of the permanent wide warm surface current, which only happened in summer but in every summer. That second summer surge either produced a second longitudinal SST maximum to the west or the two maxima blended together somewhere in between.

In the future it will be interesting to go back to the original monthly mean graph books for the two latitudes ( 35 and $40 \mathrm{~N}$ ) to see if the two longitudinal SST maxima can be separated out better before the long term averages ( 20 or 30 years) are performed on the summer month temperatures. Then it may turn out that the eastern SST maximum remains where it is during summer instead of migrating westward. But if it would go so far as to shift east in summer is an open question.

A separate and unexplained issue to take into consideration, relevant to the possibility that the wide warm surface current might be closer to California in the summer, is the observation made by the hydrographic section along $35 \mathrm{~N}$ in March and April of 1976: the SST maximum was about ten degrees of longitude west of the location of the largest mixed layer depths. In other words, what is being called the centerline here of the wide warm deep mixed layer trough was not directly underneath the SST maximum. Therefore, although the longitudinal SST maximum is a good signature of the wide warm surface current as a whole at mid-latitudes, it does not always represent the position of the middle of the current.

Finally, temperature observations showing a long trough of deep mixed layers imply (assuming negligible wind stirring) that the sea surface is being cooled from above but without specifying exactly how: conduction, evaporation, or both. What salinity data there are in the atlas do not appear to decide the question either.

\section{CONCLUSION}

A permanent wide warm surface current flowing northeast off California, initially identified in 30 years of monthly mean ship-injection temperatures, is connected up to its origin in the western tropical North Pacific by a long trough of deep mixed layers, which is also permanent based on 27 years of monthly mean BT (temperature against depth) data in a classical oceanographic atlas. Mean northeastward flow in the surface layer with heat continually leaking out into the atmosphere is consistent with the observations in the atlas. Centerline curves that join the deepest mixed layer depths within the troughs in the atlas are presented for all twelve months. These centerline curves, which may be an approximate indicator of the middle of the flow, are nearly in the same position all year long except for a moderately strong characteristic exhibited in which they come closer to California in the summer months (May through August). More studies in the future would be helpful in order to try to verify this tentative conclusion, because no such prediction ever resulted from the early mid-latitude SST analyses of the 1970s.

\section{REFERENCES}

1. Kenyon, K.E. (1981) A Shallow Northeastward Current in the North Pacific. Journal of Geophysical Research, 86, 6529-6536. https://doi.org/10.1029/JC086iC07p06529

2. Robinson, M.K. (1976) Atlas of North Pacific Ocean Monthly Mean Temperatures and Mean Salinities of the Surface Layer. Department of the Navy, Washington, DC.

3. Kenyon, K.E. (1978) The Surface Layer of the Eastern North Pacific in Winter. Journal of Geophysical Research, 83, 6115-6122. https://doi.org/10.1029/JC083iC12p06115

4. Kenyon, K.E. (1975) The Influence of Longitudinal Variations in Wind Stress Curl on the Steady Ocean Circulation. Journal of Physical Oceanography, 5, 334-346. https://doi.org/10.1175/1520-0485(1975)005<0334:TIOLVI $>2.0$. CO;2 